\title{
A proposal of injection points of botulinum toxin into temporal region for chronic migraine
}

\author{
Young Gun Kim, Jung Hee Bae, Seong Taek Kim* \\ Department of Orofacial Pain and Oral Medicine, Department of Anatomy, College of Dentistry, Yonsei University, Seoul, \\ Republic of Korea
}

Botulinum toxin (BoNT) injections have been used not only in the field of cosmetic surgery such as forehead and eye wrinkle treatment but also in the treatment of chronic migraine, dystonia, spasticity, temporomandibular disorders (TMD). BoNT injections are the only approved therapies to date for prophylactic treatment of chronic migraine patients. Unlike the previously known paralysis of motor neurons, the mechanism of action for migraine is to block the release of non-cholinergic neurotransmitters such as substance $\mathrm{P}, \mathrm{CGRP}$, and glutamate, which are associated with peripheral sensitization and neurogenic inflammation in the sensory nerve, it is hypothesized that the signal is blocked. This review focuses on the analgesic effects of BoNT and suggests the direction for the development of injection methods for chronic migraine patients. (J Dent Rehabil Appl Sci 2017;33(1):1-6)

Key words: botulinum toxin; pain; migraine; chronic headache

\begin{abstract}
서론
보툴리즘 식중독(Botulism)은 밀폐된 용기의 부패된 소시지나 육류를 섭취한 후 발생하는 식중독의 하나로 1822년 독일 Württemberg 지방의 의사 Justinus Kerner 에 의해 처음 증상이 설명되었다. 이는 복통과 구토뿐만 아니라 전신에 근육의 마비가 일어나고 호흡곤란을 야 기하는데, 1895년 Emile Pierre Marie van Ermengem 에 의하여 이 식중독으로 사망한 사체에서 혐기성 간균 Clostridium botulinum을 발견하였다.
\end{abstract}

1920년대에 들어 미국 캘리포니아 대학의 Hermann Sommer에 의해 Botulinum toxin type A (BoNT-A) 가 처음 분리되었고, 1949년 Burgen에 의하여 이 물질

*Correspondence to: Seong-Taek Kim Department of Orofacial pain and Oral Medicine, Yonsei University College of Dentistry, 50 Yonsei-ro, Seodaemun-gu, Seoul, 03722, Republic of Korea Tel: +82-2-2228-3110, Fax: +82-2-393-8076, E-mail: k8756050@yuhs,ac Received: February 1, 2017/Last Revision: March 13, 2017/Accepted: March 15, 2017
이 신경전달을 차단하는 것이 증명된 이후, 의학분야에 서 사용가능성이 대두되었다. 1981년 Alan B. Scott에 의 해 인간의 사시(strabismus)치료에 처음 적용된 이후, 사 시(strabismus), 안검경련(blepharospasm), 얼굴의 주름 (facial wrinkle), 뇌성마비(cerebral palsy), 경부근 근육긴 장이상 (cervical dystonia), 다한증(Hyperhydrosis) 등 많 은 영역에서 치료목적으로 이용되고 있다.

치과영역에서는 비록 비승인 용법(Off-label use)이긴 하나 1994년 Moore와 Wood, Smyth 등에 의해 교근비 대(masseter hypertrophy)의 치료에 사용한 증례가 보 고되었으며, 이후 측두하악장애(temporomandibular disorder), 이갈이(bruxism), 근육긴장이상(dystonia) 등 에 사용되고 있다.

Copyright@ 2017 The Korean Academy of Stomatognathic Function and Occlusion. (c) It is identical to Creative Commons Non-Commercial License. 


\section{문헌고찰}

\section{만성편두통(chronic migraine)에 대한 BoNT-A 의 효과}

만성 편두통(Chronic migraine)은 전체 인구의 1.4 $2.2 \%$ 에 영향을 미치는 신경과적 질환이다. ${ }^{1}$ 국제두통장 애분류(ICHD-3 베타)는 만성 편두통을 3개월 이상 지 속되는, 한 달에 15 일 이상 발생하는 두통으로서, 이러 한 두통발작 중 적어도 한 달에 8일 이상 특징적인 편두 통 증상을 보이는 상태로 정의한다. ${ }^{2}$ 만성 편두통은 일차 적 만성 일일 두통의 가장 흔한 유형이며 치료가 어렵다. OnabotulinumtoxinA (Botox ${ }^{\circledR}$ )는 만성편두통의 치료법 으로 미국 FDA로부터 2010년에 승인되었으며, 현재까 지 만성편두통에 대한 치료법으로 승인된 유일한 예방요 법이다. ${ }^{3}$

Botulinum toxin type A(BoNT-A)의 진통 효과는 1985년 경부근육 이상긴장증(cervical dystonia)에 대한 pilot study에서 처음 보고되었다. ${ }^{4}$ 경부근육의 이상긴장 증은 목과 어깨 근육의 비정상적이고 불수의적인 수축이 일어나 심한 근골격계통증과 장애를 유발한다. 이후로 여러 연구들에서 근막통증(myofascial pain), 측두하악장 애(temporomandibular disorder), 이갈이(bruxism), 요 통(back pain), 통증성 근육간대경련(painful myoclonus), 전립선 통증(prostatic pain), 군집성 두통(cluster headache), 긴장형 두통(tension-type headache) 및 편두통(migraine) 과 같은 수많은 통증 장애에 대한 통증 완화 효과를 조 사했다.

두통에 대한 BoNT-A의 효과에 대한 최초의 임상적 인 관찰은 환자에게 미용적인 시술을 시행하였을때 부가 적으로 나타나는 것을 통해 처음 보고되었다. 주로 얼굴 의 주름에 대한 미용적 시술은 얼굴의 표정을 짓는 근육 에 대하여 이루어졌던 바, 주사점에 대한 명명은 주로 해 당 근육에 대한 것으로 이루어졌다. 이후 선학들의 연구 에 의하여 PREEMPT 프로토콜에 이르기까지 머리와 목 부위 근육에 대한 최소 31 개의 주사 부위를 포함하는 표 준화된 방법으로 발전되었다.

BoNT-A가 보이는 진통효과는 처음에는 근육 수축 에 미치는 영향과 관련이 있다고 생각되었다. 그러나 몇 몇 연구의 결과는 근육 이완 효과가 진통효과와 직접적 으로 일치하지 않으며 BoNT-A의 진통 효과에 다른 메 커니즘이 있음을 암시한다. ${ }^{5}$ 예를 들어 BoNT-A에 의
한 진통 효과는 근육긴장도에 대한 이완 효과보다 먼저 나타나며 보다 오래 지속된다. BoNT-A가 구심성전도 (afferent transmission)에 영향을 미치고 통증인지(pain perception), 혈관확장(vasodilation) 및 신경인성 염증 (neurogenic inflammation)에 작용하는 substance-P의 방출을 억제한다는 연구결과가 있다. ${ }^{6-9}$ 또한 BoNT-A 는 CGRP 및 glutamate의 방출 또한 억제한다. 따라서 BoNT-A의 진통효과는 운동뉴런(motor neuron)과 관계 되는 아세틸콜린(acetylcholine)보다는 감각뉴런(sensory neuron)에서 신경펩타이드(neuropeptide)와 통증조절물 질(pain modulator)의 방출을 억제하기 때문이라고 추측 된다.

BoNT-A가 만성편두통에 어떠한 기전으로 작용하 는지는 현재까지 완전하게 이해되지 않고 있다. 그러 나 비정형적인 통증 조절(atypical pain processing), 중추 감작(central sensitization), 대뇌피질 과민성 (cortical hyperexcitability) 및 신경인성 염증(neurogenic inflammation)에 작용하는 기전이 연구되었다. 첫 째, BoNT-A는 말초 감각뉴런에서 신경펩타이드 (neuropeptide)와 신경전달물질(neurotransmitter) 의 exocytosis를 감쇠시킴으로써 말초감작(peripheral sensitization)을 직접 억제하며, 간접적으로 이를 통해 중 추감작(central sensitization)을 줄인다. ${ }^{10} \mathrm{CGRP}$ 와 같은 혈관에 작용하는 신경펩타이드의 과다한 방출과 이로 인 한 신경인성염증은 만성편두통의 병태생리에 작용할 수 있다.

동물연구의 결과는 BoNT-A가 삼차신경 세포로부 터 CGRP, glutamate 및 substance-P의 자극 방출을 차 단하고, 통증 신호의 전달을 담당하는 척수내 이차뉴 런의 활성화를 억제할 수 있다는 증거를 제시했다. 편 두통 발작(migraine attack) 동안, 뇌경막과 혈관주변으 로 분포하는 삼차신경 섬유의 활성화로 인해 말초감작 이 발생한다. 경막혈관의 신경인성 혈관확장(neurogenic vasodilation)은 경막 염증(dural inflammation)을 유발한 다. 실험적으로 유발된 경막 신경염증에 BoNT가 보이 는 억제작용은 동물모델에서 삼차신경 내에서 BoNT-A 의 축삭수송(axonal transport)에 의해 매개되는 것으로 밝혀졌다. ${ }^{11}$ 또한, 말초에 주사된 BoNT-A는 척수 삼차 신경핵 미측핵(spinal trigeminal nucleus caudalis; TNC) 에 축삭수송을 통해 중추로 운반될 수있다. ${ }^{12} \mathrm{TNC}$ 에서 cleaved SNAP-25의 존재는 BoNT-A가, 삼차신경으로 부터 집중적인 유해수용성 입력을 받고 중추감작을 중재 
하는, $\mathrm{TNC}$ 의 이차뉴런 레벨에서도 작용한다는 것을 의 미한다.

상기 논의된 바와 같이, BoNT-A는 감각뉴런에 영향을 주어 진통효과를 나타내기 때문에, 만성편두통에 대한 BoNT-A주사는 근육내의 운동신경이 아닌, 삼차신경-경 부신경 복합체에서 감각신경을 표적으로 해야한다.

\section{측두영역(temporal area)의 BoNT-A injection}

측두이개신경(auriculotemporal nerve; ATN)은 측두 영역의 감각을 지배하는 주된 신경이다. 이 신경은 삼차 신경(trigeminal nerve)의 가지인 하악신경(mandibular nerve)에서 일어나고 처음에는 깊은 층(deep layer)을 주 행하다가 측두하악관절(TMJ)근처의 영역에서 표면층 (superficial layer)으로 올라온다. BoNT-A 주사 법의 적 절한 주사점을 선정하기 위해서, 먼저 일관되고 재현성이 있는 해부학적 지표를 정해야 한다. PREEMPT 프로토 콜은 측두근(temporalis muscle)의 전방경계선과 헤어라 인을 지표로 사용하지만, 헤어라인이 개개인 사이에서 헤 어스타일에 따라 현저하게 변하기 때문에 일관성이나 재 현성이 떨어진다. 따라서, 주사점의 지표는 보다 해부학 적으로 재현이 가능한 골격이나 해부학구조를 기반으로 해야한다.

Baumel (1971)은 ATN의 해부학에 대한 연구를 보 고했다. ${ }^{13}$ 이 신경은 하악신경 줄기의 뒷부분에서 발생 하는 두 개의 뿌리에 의해 형성된다. 일반적으로 총 6개 의 주된 가지로 나뉜다. 얼굴 신경과 소통하는 두개의 신 경, 외이도로 분포하는 두개의 신경, 전이개신경(anterior auricular nerve), 표층 측두부 신경가지(superficial temporal ramus). 이 중 만성편두통에 대한 주사요법에서 주로 타 겟이 되는 것은 표층 측두부 신경가지이다. 표층 측두부 신경가지는 ATN의 가장 큰 단일 말단 분지이며, 처음에 는 외측으로 주행하다가 측두하악관절부에 몇 개의 가 지를 공급하면서 관절의 뒤쪽으로 통과한다. 이후 표층 부로 올라오면서 상방으로 주행하여 관골궁의 기시부를 가로지르며 표층측두동맥(superficial temporal artery)의 후내측에 위치한다(Fig. 1).

최초에 미국 FDA로부터 승인받은 PREEMPT 프로 토콜에 의한 측두 부위 주사법은 다음과 같다. ${ }^{14}$ 측두근 의 전방경계를 찾기 위하여 환자는 이를 꽉 물도록 하면 서 술자가 촉진하여 위치를 찾는다. 첫 번째 주사점은 측 두근의 전방경계 바로 뒤쪽으로, 헤어라인으로부터 손

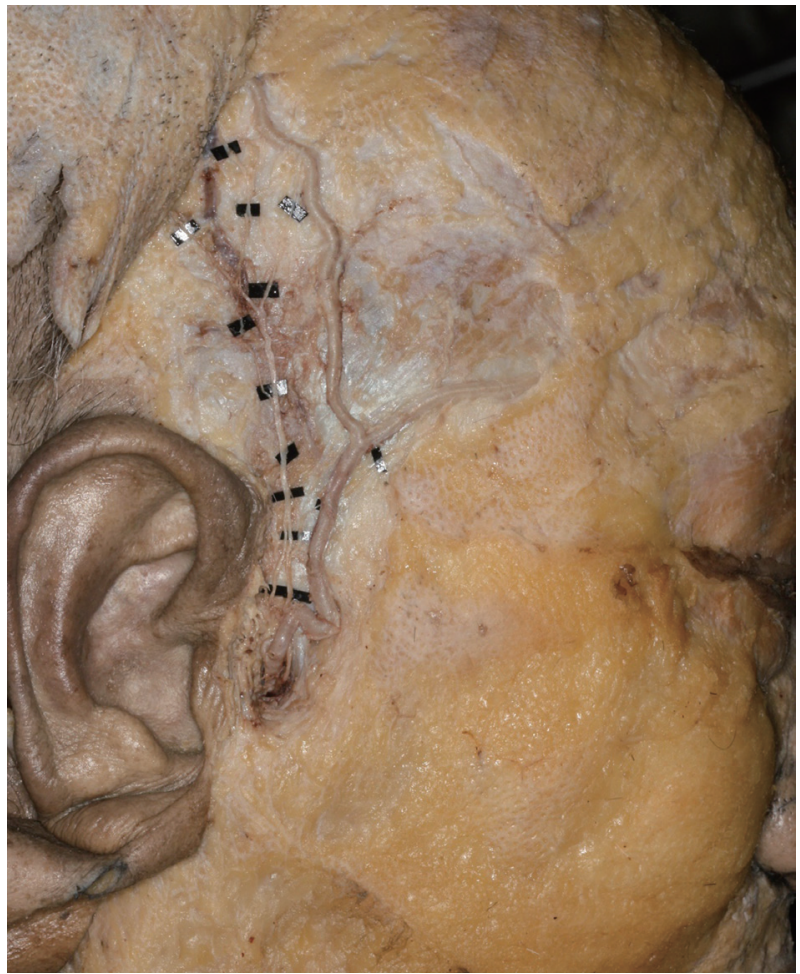

Fig. 1. Photographs showing the superficial layer of ATN distribution.

가락 두개 너비 뒤로 위치한다. 두번째 주사점은 근육 의 내측면(medial aspect)에서 첫번째 주사점보다 약 0.5 $\mathrm{cm}$ 위쪽 및 $1.5 \mathrm{~cm}$ 뒤쪽에서 위치한다. 세번째 주사점 은 두번째 주사점으로부터 평행하게 약 $1.5 \mathrm{~cm}$ 후방에 위치한다. 네번째 주사점은 두번째 주사점으로부터 1.5 $\mathrm{cm}$ 수직아래로 근육의 내측면에 위치한다. 이후 2013 년 Ashkenazi와 Blumenfeld는 감각신경의 분포를 고려 하여 만성편두통의 치료에 대한 주사점을 제안했다..$^{15}$ 이 들은 귀의 이주(tragus)를 촉진하여 이로부터 수직으로 3 $\mathrm{cm}$ 상방에 첫번째 자입점을 잡는다. 동일한 수직선상으 로 $1.5 \mathrm{~cm}$ 상방에 두번째 자입점을 잡는다. 세번째 자입 점은 처음 두 주입 지점 사이, $1.5 \mathrm{~cm}$ 전방에 잡는다. 마 지막으로 네번째 자입은 두번째 자입점으로부터 후방으 로 $1.5 \mathrm{~cm}$ 에 시행한다. 기존 PREEMPT와 Ashkenazi 연 구의 자입점 비교는 Fig. 2과 같다. 


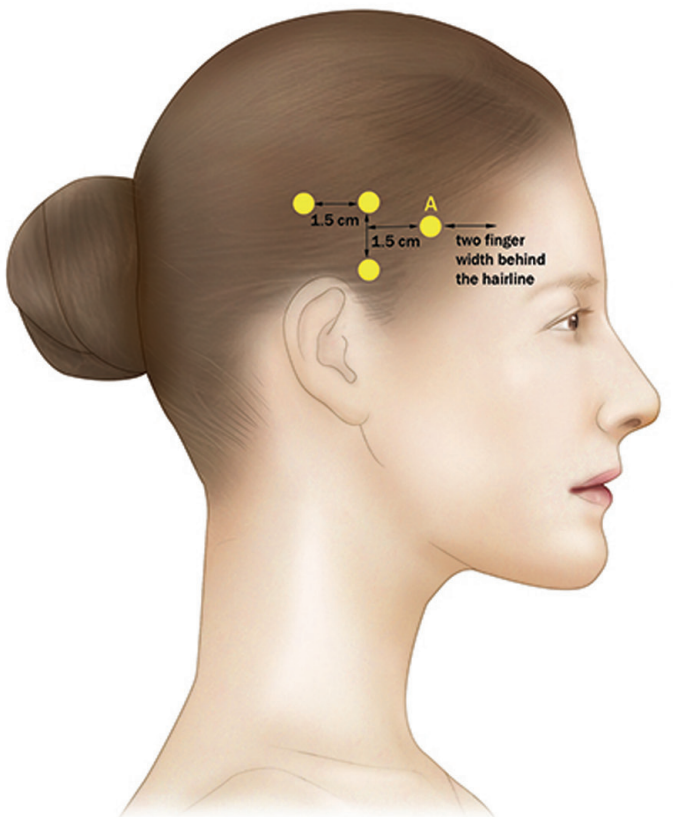

A

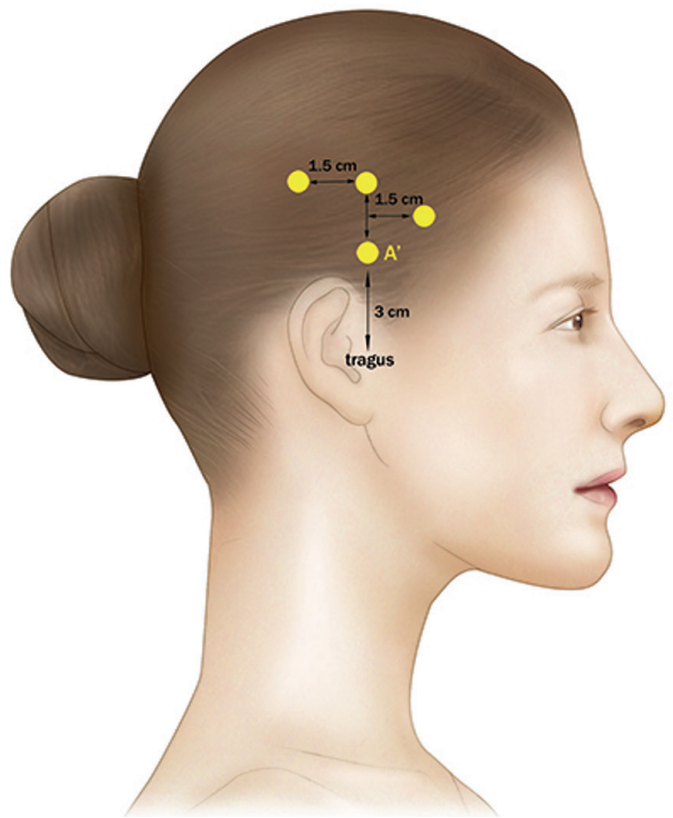

B

Fig. 2. Schematics comparing different injection protocols: (A) PREEMPT (2010) ${ }^{14}$, (B) Ashkenazi and Blumenfeld (2013) ${ }^{15}$.

\section{결론}

상기에서 살펴본 바와 같이, 만성편두통환자에서의 BoNT-A는 기존의 근육에 대한 작용과는 달리 감각신경 을 주된 타겟으로 삼아야 한다. 이에 따라 감각신경을 위 주로 하는 새로운 주사법이 제안되었으나 해부학적인 연 구결과에 기반하고 있지는 않다는 한계점이 있다. 따라 서 추후 측두영역의 감각신경분포에 대한 해부학적인 연 구의 진행필요성이 있으며, 이를 기반으로 한 새로운 주 사법이 연구되어져야 할 것으로 사료된다.

\section{Acknowledgements}

본 연구는 연세대학교 치과대학 2015년도 교수연구비 (6-2015-0107)의 지원을 받아 이루어졌음.

\section{References}

1. Natoli JL, Manack A, Dean B, Butler Q, Turkel CC, Stovner L, Lipton RB. Global prevalence of chronic migraine: a systematic review. Cephalalgia 2010;30:599-609.
2. Headache Classification Committee of the International Headache Society (IHS). The international classification of headache disorders, 3rd edition (beta version). Cephalalgia 2013;33:629-808.

3. U.S. Food and Drug Administration. FDA approves Botox to treat chronic migraine. Available from: https://wayback.archive-it.org/7993/ 20170112032340/http://www.fda.gov/NewsEvents/Newsroom/PressAnnouncements/2010/ ucm229782.htm (updated 2017 Feb 1).

4. Tsui JK, Eisen A, Mak E, Carruthers J, Scott A, Calne DB. A pilot study on the use of botulinum toxin in spasmodic torticollis. Can J Neurol Sci 1985;12:314-6.

5. Wheeler A, Smith HS. Botulinum toxins: mechanisms of action, antinociception and clinical applications. Toxicology 2013;306:124-46.

6. Durham PL, Cady R. Insights into the mechanism of onabotulinumtoxinA in chronic migraine. Headache 2011;51:1573-7.

7. Filippi GM, Errico P, Santarelli R, Bagolini B, Manni E. Botulinum A toxin effects on rat jaw muscle spindles. Acta Otolaryngol 1993;113:400-4. 
8. Ishikawa H, Mitsui Y, Yoshitomi T, Mashimo K, Aoki S, Mukuno K, Shimizu K. Presynaptic effects of botulinum toxin type A on the neuronally evoked response of albino and pigmented rabbit iris sphincter and dilator muscles. Nippon Ganka Gakkai Zasshi 2001;105:218-22.

9. Rosales RL, Arimura K, Takenaga S, Osame M. Extrafusal and intrafusal muscle effects in experimental botulinum toxin- $\mathrm{A}$ injection. Muscle Nerve 1996;19:488-96.

10. Aoki KR. Review of a proposed mechanism for the antinociceptive action of botulinum toxin type A. Neurotoxicology 2005;26:785-93.

11. Filipović B, Matak I, Bach-Rojecky L, Lackovi Z. Central action of peripherally applied botulinum toxin type $\mathrm{A}$ on pain and dural protein extravasation in rat model of trigeminal neuropathy. PloS
One 2012;7:e29803.

12. Matak I, Bach-Rojecky L, Filipović B, Lacković Z. Behavioral and immunohistochemical evidence for central antinociceptive activity of botulinum toxin A. Neuroscience 2011;186:201-7.

13. Baumel JJ, Vanderheiden JP, McElenney JE. The auriculotemporal nerve of man. Am J Anat 1971; 130:431-40.

14. Blumenfeld A, Silberstein SD, Dodick DW, Aurora SK, Turkel CC, Binder WJ. Method of injection of onabotulinumtoxinA for chronic migraine: a safe, well-tolerated, and effective treatment paradigm based on the PREEMPT clinical program. Headache 2010;50:1406-18.

15. Ashkenazi A, Blumenfeld A. OnabotulinumtoxinA for the treatment of headache. Headache 2013;53 Suppl 2:54-61. 


\section{만성편두통 치료를 위한 측두 부위의 보툴리눔 독소 주사 자입점 제시}

\section{김영건, 배정희, 김성택*}

연세대학교 치과대학 구강내과학교실, 해부학교실

보툴리눔 독소 주사는 이마, 눈가 주름치료 등 미용성형분야 뿐만 아니라 만성 편두통(chronic migraine), 근육긴장이상 (dystonia), 경직(spasticity), 측두하악장애의 치료 등에 사용되어 왔다. 특히 보툴리눔 독소 주사는 만성편두통환자의 예 방적 치료요법으로 현재까지 유일하게 승인된 요법이다. 기존에 잘 알려진 운동신경에서의 마비효과와는 달리, 편두통에 대한 작용기전은 감각신경에서 말초감작과 신경원성염증과 관련되는 substance P, CGRP, glutamate 등 비콜린성 신경전 달물질의 유리를 차단하여 통증신호를 차단하는 역할을 한다는 가설이 제기되고 있다. 본 논문에서는 보툴리눔독소가 갖는 진통효과에 대한 고찰과 함께 이를 통하여 추후 만성편두통환자에 대한 주사법 개발에 대한 방향성을 제시하고자 한다.

(구강회복응용과학지 2017;33(1):1-6)

주요어: 보툴리눔 독소; 통증; 편두통; 만성두통 